\title{
Impact of Endoscopic Ultrasound in Evaluation of Upper Abdominal Pain
}

\author{
Bimal Chandra Shil ${ }^{* 1}$, Madhusudan Saha ${ }^{2}$, Md. Royes Uddin ${ }^{3}$, A N M Saifullah ${ }^{4}$, \\ Md. Rehan Habib 5 , Imteaz Mahbub ${ }^{6}$, Mamun -Ur Rashid ${ }^{7}$
}

\begin{abstract}
Introduction: Upper abdominal pain is found to be one of the most common presenting symptoms. Endoscopic ultrasound may be a useful tool to yield a specific diagnosis. Aim of our study was to find the etiology of upper abdominal pain with normal endoscopic findings and compare the findings of endoscopic ultrasound with those of trans-abdominal ultrasound. Materials and Methods: This was a cross sectional study conducted in the department of gastroenterology, Sir Salimullah Medical College from January 2015 to December 2019. Total 238 patients suffering from upper abdominal pain who previously underwent endoscopy with normal results and trans abdominal ultrasound with doubtful findings were enrolled in this study. All patients were evaluated properly with history, clinical examination and relevant blood investigations. Then the patients underwent endoscopic ultrasound with conscious sedation. Computed tomorgraphy, magnetic resonance cholangiopancreatography and endoscopic retrograde cholangiopancreatography were done in cases where needed and correlated with endoscopic ultrasound results. Results: Among the total 238 patients, 137 were male and 101 were female. Most predominant age range was 31-40 years. Pain was moderate in severity in 43.27\%, epigastric pain was in $59.66 \%$ and pain referred to back was in $37.39 \%$ patients. Comparison with trans abdominal ultrasound regarding etiologies of upper abdominal pain was statistically significant $(P=0.000)$. Comparative analysis between the two modalities regarding gall bladder, common bile duct, pancreas were also found significant with $P$ values of 0.040, 0.005, 0.000 respectively. Forty two patients were diagnosed as chronic pancreatitis based on Rosemont criteria by endoscopic ultrasound. Conclusion: Endoscopic ultrasound is a modern diagnostic tool which can detect hepato-pancreato-biliary pathologies and also mucosal irregularities of stomach and esophagus. So, it can be considered as a first line investigation to diagnose the underlying etiology of upper abdominal pain.
\end{abstract}

Keywords: Upper abdominal pain, Endoscopic ultrasound, Endoscopy, Trans abdominal ultrasound.

Number of Tables: 07; Number of References: 43; Number of Correspondence: 06.

*1. Corresponding Author:

Professor Bimal Chandra Shil

Professor \& Head, Department of Gastroenterology

Sir Salimullah Medical College, Dhaka.

Email: drbimalshil@gmail.com

Mobile:+8801720038611

2. Professor Madhusudan Saha

Professor, Department of Gastroenterology

Northeast Medical College Hospital, Sylhet.

3. Dr. Md. Royes Uddin

Assistant Professor, Department of Gastroenterology Sir Salimullah Medical College, Dhaka.

4. Dr. A N M Saifullah

Assistant Professor, Department of Gastroenterology

Sir Salimullah Medical College, Dhaka.

5. Dr. Md. Rehan Habib

Assistant Professor, Department of Gastroenterology Sir Salimullah Medical College, Dhaka.

6. Dr. Imteaz Mahbub

MD Resident (Phase-B), Department of Gastroenterology

Sir Salimullah Medical College, Dhaka.

7. Dr. Mamun -Ur Rashid

Junior Consultant, Department of Medicine

OSD (DGHS), Dhaka.
Introduction:

In primary health care settings throughout the world, upper abdominal pain is found to be one of the most common presenting symptoms ${ }^{1}$. In fact, almost one fourth to one third adults seek medical amenities for upper abdominal pain annually. If reflux symptoms are included then it is about $40 \%$ of total adult patients ${ }^{2}$. Moreover, the incidence of unexplained abdominal pain is around $2 \%$ to $3 \% 0^{3,4,5}$. The differential diagnoses seen starting from functional dyspepsia, peptic ulcer disease and cholelithiasis to more unusual diagnoses such as choledocholithiasis, sphincter oddi dysfunction, chronic pancreatitis and upper gastrointestinal malignancies. But many of these conditions are difficult to exclude without invasive procedures and patients may need to undergo esophagogastroduodenoscopy, ultrasound and computed tomography for confirm diagnosis ${ }^{6}$. With all these efforts, many of these cases may yet not be diagnosed ${ }^{7}$. In this context, Endoscopic ultrasound (EUS) may be a useful tool to yield a specific diagnosis.

Endoscopic ultrasound came into light in the early $1980 \mathrm{~s}^{8}$. It is a specialized endoscope which combines endoscopy and ultrasound to obtain images and information of the digestive tract and its surrounding organs ${ }^{6}$. In this technology, ultrasound transducer is placed within the body so that the distance between transducer and region of interest is reduced by avoiding air filled or bony structures ${ }^{9}$, $10,11,12,13,14$. It can successfully obtain clear images and information 
regarding the layers of the intestinal wall, lymph nodes, sub mucosal lesions and the blood vessels. Another important aspects of EUS is that it can obtain ultrasound guided tissue samples from suspicious lesions ${ }^{15}$.

The established diagnostic indications of endoscopic ultrasound are detection of cholelithiasis, microlithiasis, choledocholithiasis, worm in common bile duct, evaluation of submucosal lesions, pancreatic cysts, diagnosis of acute/chronic pancreatitis, pancreatic calculi, diagnosis and staging of gastrointestinal, pancreaticobiliary and lung cancers $^{16}$

As endoscopic ultrasound has both endoscopy and ultrasound in a single entity, performing this modality in the diagnosis of upper abdominal pain may maximize additional benefits ${ }^{17}$. But there are a very few studies regarding utility of endoscopic ultrasound in detecting etiologies of upper abdominal pain with normal upper GI endoscopic findings. This study was designed to find out the etiology of upper abdominal pain with normal endoscopic findings and compare the results of endoscopic ultrasound (EUS) with trans-abdominal ultrasound (TUS) findings of patients with upper abdominal pain.

Materials and Methods:

This was a cross sectional study conducted in the department of gastroenterology, Sir Salimullah Medical College Mitford hospital, Dhaka from January 2015 to December 2019. Total 238 patients suffering from upper abdominal pain who previously underwent endoscopy with normal findings and trans abdominal ultrasound were enrolled in this study. Inclusion criteria for the patients were: Age over 18 years and upper abdominal pain defined as frequent $(>6$ episodes in previous 12 months) pain or discomfort in the upper abdomen (above the umbilicus). Exclusion criteria included: dysphagia, oesophageal varices, malignancy, bleeding, patients with comorbidities and previous gastric surgery.

Informed consent was taken from all cases; all patients were evaluated properly with history, clinical examination and relevant blood investigations. All the patients underwent Endoscopic ultrasound with conscious sedation. It was carried out by Fujinon echoendoscope (Model EG-530 $\mathrm{UR}_{2}$ for radial array and E-530 $\mathrm{UT}_{2}$ for linear array). The findings of endoscopic ultrasound were recorded and compared with those of trans-abdominal ultrasound of respective patients. Computed tomography scan of abdomen, Magnetic resonance imaging/ cholangiopancreatography and endoscopic retrograde cholangiopancreatography were done in cases where needed and correlated with endoscopic ultrasound results to reach the diagnoses. The statistical analysis was done by SPSS 22.0 software (SPSS, Inc. USA). Statistical significance was calculated by Students't test. Statistical significances of the study was set at $<0.05$.

\section{Results:}

Total 238 patients took part in the study. Of them 137 were male and 101 were females with predominant age range was 31-40 years.
Table I: Demographic characteristics of the 238 patients.

\begin{tabular}{lcc}
\hline Parameter & Frequency & Percentage \\
\hline Sex & 137 & \\
Male & 101 & $57.56 \%$ \\
Female & & $42.44 \%$ \\
Age (Years) & 46 & \\
$18-30$ & 58 & $19.33 \%$ \\
$31-40$ & 54 & $24.37 \%$ \\
$41-50$ & 43 & $22.69 \%$ \\
$51-60$ & 23 & $18.07 \%$ \\
$61-70$ & 14 & $9.66 \%$ \\
$>70$ & 238 & $5.88 \%$ \\
Total & & $100 \%$ \\
\hline
\end{tabular}

Clinical characteristics of chronic upper abdominal pain are given in table II. It shows pain was mostly moderate $(43.27 \%)$, in epigastric region $(59.66 \%)$ and referred to back $(37.39 \%)$

Table II: Clinical Characteristics of pain.

\begin{tabular}{lcl}
\hline Parameter & Frequency & Percentage \\
\hline Intensity & 58 & $24.37 \%$ \\
Severe & 103 & $43.27 \%$ \\
Moderate & 77 & $32.35 \%$ \\
Mild & & \\
Location & 142 & $59.66 \%$ \\
Epigastrium & 63 & $26.47 \%$ \\
RUQ & 28 & $11.76 \%$ \\
LUQ & 05 & $2.10 \%$ \\
Central abdomen & & \\
Referred Pain & 137 & $57.56 \%$ \\
Nil & 89 & $37.39 \%$ \\
Back & 12 & $5.04 \%$ \\
Shoulder & &
\end{tabular}

Various etiologies detected by endoscopic ultrasound and along with its comparison with trans abdominal ultrasound is shown in table III which is statistically significant $(\mathrm{P}=0.000)$.

Table III: Etiologies of abdominal pain.

\begin{tabular}{lccc}
\hline Causes & $\begin{array}{c}\text { Endoscopic } \\
\text { Ultrasound }\end{array}$ & $\begin{array}{c}\text { Trans Abdominal } \\
\text { Ultrasound }\end{array}$ & P Value \\
\hline Calculous Cholecystitis & $48(20.17 \%)$ & $45(18.91 \%)$ & 0.0000 \\
Microlithiasis with Cholecystitis & $10(4.20 \%)$ & $02(0.84 \%)$ & \\
GB sludge & $24(10.08 \%)$ & $19(9.24 \%)$ & \\
GB Mass & $3(1.26 \%)$ & $1(0.42 \%)$ & \\
Worm in GB & $1(0.42 \%)$ & $0(0.00 \%)$ & \\
Acalculous Cholecystitis & $04(1.68 \%)$ & $09(3.78 \%)$ & \\
Biliary Ascariasis & $06(2.52 \%)$ & $02(0.84 \%)$ & \\
Choledocholithiasis & $76(31.93 \%)$ & $65(28.15 \%)$ & \\
Acute Pancreatitis & $36(15.13 \%)$ & $32(13.45 \%)$ & \\
Chronic Pancreatitis & $42(17.65 \%)$ & $14(5.88 \%)$ & \\
Ca Pancreas & $06(2.52 \%)$ & $1(0.42 \%)$ & \\
No cause Found & $05(2.10 \%)$ & $48(20.17 \%)$ & \\
\hline
\end{tabular}

Table IV shows the gall bladder findings of endoscopic ultrasound and trans abdominal ultrasound and their comparison which is statistically significant $(\mathrm{P}=0.04)$.

Table IV: Findings of Gall bladder at Endoscopic ultrasound and Trans abdominal ultrasound.

\begin{tabular}{lccc}
\hline Parameter & Endoscopic Ultrasound & $\begin{array}{c}\text { Trans Abdominal } \\
\text { Ultrasound }\end{array}$ & P Value \\
\hline Normal & $108(45.38 \%)$ & $126(52.94 \%)$ & 0.04 \\
Calculous Cholecystitis & $48(20.17 \%)$ & $46(19.33 \%)$ & \\
Microlithiasis & $10(4.20 \%)$ & $2(0.84 \%)$ & \\
GB sludge & $24(10.08 \%)$ & $22(9.24 \%)$ & \\
Acalculous Cholecystitis & $4(1.68 \%)$ & $8(3.36 \%)$ & \\
Worm & $1(0.42 \%)$ & $0(0.00 \%)$ & \\
GB Mass & $3(1.26 \%)$ & $1(0.42 \%)$ & \\
Microlithiasis+GB sludge & $7(2.94 \%)$ & $0(0.00 \%)$ & \\
Cholelithiasis+GB sludge & $3(1.26 \%)$ & $3(1.26 \%)$ & \\
Absent Gall bladder & $30(12.61 \%)$ & $30(12.61 \%)$ & \\
Total & 238 & 238 & \\
\hline
\end{tabular}

Table V shows comparative findings of endoscopic and trans abdominal ultrasound in case of bile duct lesions with significance of 0.005 . 
Table V: Findings of Bile ducts at Endoscopic ultrasound and Trans abdominal ultrasound.

\begin{tabular}{lccc}
\hline Parameter & $\begin{array}{c}\text { Endoscopic } \\
\text { Ultrasound }\end{array}$ & $\begin{array}{c}\text { Trans Abdominal } \\
\text { Ultrasound }\end{array}$ & P Value \\
\hline Normal & $65(27.31 \%)$ & $98(41.18 \%)$ & 0.005 \\
Dilated & $54(22.69 \%)$ & $38(15.97 \%)$ & \\
Stone & $6(2.52 \%)$ & $2(0.84 \%)$ & \\
Sludge & $6(2.52 \%)$ & $1(0.42 \%)$ & \\
SOL suggesting neoplasm & $5(2.10 \%)$ & $1(0.42 \%)$ & \\
Worm & $6(2.52 \%)$ & $2(0.84 \%)$ & \\
Dilated+Stone & $70(29.41 \%)$ & $63(26.47 \%)$ & \\
Dilated+SOL & $16(6.72 \%)$ & $11(4.62 \%)$ & \\
Dilated+Sludge & $6(2.52 \%)$ & $1(0.42 \%)$ & \\
Dilated+Stricture & $4(1.68 \%)$ & $2(0.84 \%)$ & \\
Total & 238 & 238 & \\
\hline
\end{tabular}

Table VI shows comparison of pancreatic findings with endoscopic ultrasound's superiority over abdominal ultrasound with statistical significance $\mathbf{P}<0.0001$.

Table VI: Findings of Pancreas at Endoscopic ultrasound and Trans abdominal ultrasound.

\begin{tabular}{lccc}
\hline Parameter & $\begin{array}{c}\text { Endoscopic } \\
\text { Ultrasound }\end{array}$ & $\begin{array}{c}\text { Trans Abdominal } \\
\text { Ultrasound }\end{array}$ & P Value \\
\hline Pancreatic Size & & & 0.000 \\
Normal & $194(81.51 \%)$ & $203(85.29 \%)$ & \\
Swollen & $36(15.13 \%)$ & $32(13.45 \%)$ & \\
Smaller Size & $8(3.36 \%)$ & $3(1.26 \%)$ & \\
Total & 238 & 238 & 0.000 \\
Pancreatic Parenchyma & & & \\
Normal & $204(85.71 \%)$ & $216(90.76 \%)$ & \\
Hyperechoic foci & $12(4.20 \%)$ & $08(3.36 \%)$ & \\
Hyperechoic strand & $10(4.20 \%)$ & $06(2.52 \%)$ & \\
Hyperechoic foci+strand & $12(5.04 \%)$ & $08(3.36 \%)$ & \\
Total & 238 & 238 & \\
Pancreatic duct & & & \\
Normal & $202(84.87 \%)$ & $205(86.13 \%)$ & \\
Main duct dilatation & $13(5.46 \%)$ & $15(6.30 \%)$ & \\
Main duct irregularity & $03(1.26 \%)$ & $03(1.26 \%)$ & \\
Calcification & $04(1.68 \%)$ & $05(2.10 \%)$ & \\
MPD dilatation & $10(4.20 \%)$ & $08(3.36 \%)$ & \\
MPD irregularity & $03(1.26 \%)$ & $02(0.84 \%)$ & \\
Worm in MPD & $03(1.26 \%)$ & $00(0.00 \%)$ & \\
Total & 238 & 238 & \\
\hline
\end{tabular}

Table VII shows number of chronic pancreatitis patients diagnosed through Rosemont criteria by endoscopic ultrasound.

Table VII: Diagnosis of Chronic Pancreatitis with Endoscopic ultrasound (Rosemont criteria).

\begin{tabular}{lcc}
\hline Parameter & Endoscopic Ultrasound & Percentage \\
\hline Consistent with CP & 25 & $10.50 \%$ \\
Suggestive of CP & 17 & $7.14 \%$ \\
Indeterminate & 21 & $8.82 \%$ \\
Normal & 175 & $73.53 \%$ \\
Total & 238 & $100 \%$ \\
\hline
\end{tabular}

\section{Discussion:}

Upper abdominal pain is a very common morbidity in day to day practice. Causes may vary from benign to malignant ${ }^{6}$. Yet many patients have no structural diseases which makes the detection of real diagnosis a difficult job ${ }^{1,18,19}$. For the purpose of yielding definitive diagnosis, patients undergo different invasive and noninvasive procedures like endoscopy ${ }^{20}$ trans abdominal ultrasound ${ }^{21}$ and computed tomography ${ }^{5}$. According to American College of Gastroenterology, upper gastrointestinal endoscopy is the first step in the diagnosis of dyspepsia of patients older than 55 years or those having alarm symptoms ${ }^{22,23}$. In a recently conducted study, it was found that among the patients with upper abdominal pain referred for further evaluation $40 \%$ had undergone previous upper gastrointestinal endoscopy, $65 \%$ had a trans abdominal ultrasound, $70 \%$ had a computed tomography and $10 \%$ had an magnetic resonance imaging ${ }^{24}$. Endoscopic ultrasound, a specialized instrument which combines both endoscopy and ultrasound may be very effective in diagnosing cases of upper abdominal pain.

Our study was conducted on 238 patients referred to our department for upper abdominal pain. Our demographic data showed, males were $137(57.56 \%)$ and females were $101(42.44 \%)$ in number with slight male predominance. It differs from the studies conducted by Thompson et $\mathrm{al}^{6}$ and Chang et $\mathrm{al}^{17}$. Both the studies showed female predominance with upper abdominal pain symptoms. Possible explanation of this sex difference in our study is that males are more aware of their health problems and also keen to seek physician's advice than women in our country. Most common age groups suffering from upper abdominal pain in our study were $31-40$ and $41-50$ years group with 58 $(24.37 \%)$ and $54(22.69 \%)$ in number respectively. This data is almost identical with the data of Chang et al ${ }^{17}$ where mean age was $48.6 \%$.

Etiologies of upper abdominal pain was searched and compared with the findings of trans abdominal ultrasound which yielded statistical significance $(\mathrm{P}=0.000)$. Most common etiologies were gall bladder disease $(37.81 \%)$, choledocholithiasis (34.45\%), acute pancreatitis (15.13\%) and chronic pancreatitis (17.65\%). Chang et al ${ }^{17}$ showed gall bladder disease as the most common cause of chronic upper abdominal pain with frequency of $32 \%$ which is almost similar to our frequency of gall bladder disease of $37.81 \%$.

Different studies have been conducted describing endoscopic ultrasound as adjunctive to trans abdominal ultrasound for detecting gall bladder lesions ${ }^{25,26,27}$. But our study tried to compare the efficacy of endoscopic ultrasound with trans abdominal ultrasound in detecting gall bladder lesions and we found endoscopic ultrasound to be superior than trans abdominal ultrasound with statistical significance $(\mathrm{P}=0.04)$. Sugiyama et al showed the superiority of endoscopic ultrasound over trans abdominal ultrasound for diagnosis of common bile duct pathologies ${ }^{28}$. Our study showed efficiency of endoscopic ultrasound to detect the common bile duct lesions which were missed in trans abdominal ultrasound. This comparison between the two modalities was found to be significant $(\mathrm{P}=0.005)$. Endoscopic ultrasound was proved to be excellent in diagnosing gall bladder and common bile duct microlithiasis and sludge in abdominal ultrasound negative patients in a study conducted in $\operatorname{Iran}^{25}$. It showed $60 \%$ patients had common bile duct stones, sludges and microlithiasis in endoscopic ultrasound who did not have any lesions in trans abdominal ultrasound. In comparison, our study found $52 \%$ had pathologies of common bile duct in endoscopic ultrasound who had absolutely normal common bile duct in trans abdominal ultrasound. In fact, in a previous study of our centre, gall bladder and common bile duct microlithiasis and sludge are found to be the main reason behind idiopathic acute pancreatitis ${ }^{29}$. 
Endoscopic ultrasound is superior to Trans abdominal ultrasound, Computed tomography, Magnetic resonance imaging in detecting pancreatic pathologies specially solid lesions and neuroendocrine tumors ${ }^{15,30,31,32,33,34}$. In our study 36 cases have increased pancreatic size (swollen pancreas) by Endoscopic ultrasound and 32 cases have increased pancreatic size by Trans abdominal ultrasound. As the Endoscopic ultrasound see the pancreas from close proximity, it detects pancreatic change better. In fact, important role of Endoscopic ultrasound in acute pancreatitis is to exclude biliary causes to avoid unnecessary Endoscopic retrograde cholangiopancreatography.

Studies suggested that Endoscopic ultrasound is more sensitive for detecting the parenchymal changes of chronic pancreatitis before the development of ductal lesions visible at Endoscopic retrograde cholangiopancreatography. So, it may serve better to diagnose early chronic pancreatitis ${ }^{35,36}$. Pancreatic parenchymal change detected in our study by endoscopic ultrasound in comparison to trans abdominal ultrasound yielded statistical significance $(\mathrm{P}=0.000)$. In this study main pancreatic duct (MPD) dilatation, duct irregularity and calcification are more detected by Endoscopic ultrasound compared to Trans abdominal ultrasound with statistical significance $(\mathrm{P}=0.000)$. There are different methods for revealing prevalence of chronic pancreatitis in patients with upper abdominal pain. Studies which were based on pancreatic function tests showed prevalence ranging from $22 \%$ to $35 \%$ in patients with dyspepsia ${ }^{37,38,39}$. Prevalence of chronic pancreatitis in patients of upper abdominal pain based on Endoscopic ultrasound found in various studies varied from $3 \%$ to $39 \%, 6,17,18,40,41$. Such dissimilarity may be due to differences in inclusion and exclusion criteria, duration of studies, characteristic of abdominal pain, criteria used for diagnosis and hospital settings. We followed Rosemont criteria for diagnosis of chronic pancreatitis. It includes hyperechoic foci with shadowing, main PD calculi and lobularity with honeycombing have been defined as major criteria while the minor criteria for CP include cysts, dilated duct $\geq 3.5 \mathrm{~mm}$, irregular PD contour, dilated side branches $\geq 1 \mathrm{~mm}$, hyperechoic duct wall, hyperechoic strand, non-shadowing hyperechoic foci and lobularity with noncontiguous lobules ${ }^{42,43}$. We diagnosed 42 cases of chronic pancreatitis where 25 cases were consistent with chronic pancreatitis while 17 cases were suggestive. Prevalence was $17.64 \%$ which is almost similar to the prevalence of the study of Atsawarungruangkit et $\mathrm{al}^{7}$ of $19.6 \%$ while differs from the prevalence recorded by Sahai et $\mathrm{al}^{18}$ of $39 \%$.

There were some limitations of our study. All the patients included in the study were referred to our center. So, there are chances of confounding factors and referral bias. Moreover, cost effectiveness was not addressed in the study.

Conclusion:

Endoscopic ultrasound is an important diagnostic tool. It can detect pathologies in liver, pancreas, gallbladder and biliary tree. It can also find out the mucosal irregularities within the stomach and esophagus. It can certainly be used to diagnose the underlying pathology of upper abdominal pain.

\section{Conflict of Interest: None.}

\section{Acknowledgement:}

The authors are grateful to the referring physicians and surgeons for their referral and also thankful to study subjects for their active, sincere and voluntary participation.

\section{References:}

1. Grimpen F, Pavli P. Rational investigation of upper abdominal pain. Aust Fam Physician. 2008 Aug; 37(8):602-7.

2. Talley NJ, Silverstein MD, Agréus L, Nyren O, Sonnenberg A, Holtmann G. AGA technical review: evaluation of dyspepsia. American Gastroenterological Association. Gastroenterology. 1998 Mar; 114(3):582-95.

https://doi.org/10.1016/S0016-5085(98)70542-6

3. Wallander MA, Johansson S, Ruigómez A, García Rodríguez LA. Unspecified abdominal pain in primary care: the role of gastrointestinal morbidity. Int J Clin Pract. 2007 Oct; 61(10):1663-70.

https://doi.org/10.1111/j.1742-1241.2007.01529.x PMid: 17681003

4. Ketwaroo GA, Freedman SD, Sheth SG. Approach to patients with suspected chronic pancreatitis: a comprehensive review. Pancreas. 2015 Mar; 44(2):173-80.

https://doi.org/10.1097/MPA.0000000000000239

PMid:25675419

5. Nojkov B, Duffy MC, Cappell MS. Utility of repeated abdominal CT scans after prior negative CT scans in patients presenting to ER with nontraumatic abdominal pain. Dig Dis Sci. 2013 Apr; 58(4): 1074-83.

https://doi.org/10.1007/s10620-012-2473-0

PMid:23179149

6. Thompson MB, Ramirez JC, De La Rosa LM, Wood AS, Desai S, Arjunan A, et al. Endoscopic ultrasound in the evaluation of chronic upper abdominal pain of unknown etiology: a retrospective chart review examining the efficacy of EUS in determining a new diagnosis. J Clin Gastroenterol. 2015 Feb; 49(2):e17-20.

https://doi.org/10.1097/MCG.0000000000000174

PMid:25569224

7. Atsawarungruangkit A, Pongprasobchai S, Pausawasdi N, Prachayakul V, Leelakusolvong S. Prevalence and Predictors of Chronic Pancreatitis in patients with Chronic Abdominal Pain with Negative Endoscopy and CrossSectional imaging. J Med Assoc Thai. 2018; 101: 521-7.

8. DiMagno EP, Buxton JL, Regan PT, Hattery RR, Wilson DA, Suarez JR, et al. Ultrasonic endoscope. Lancet. 1980 Mar 22; 1(8169):629-31.

https://doi.org/10.1016/S0140-6736(80)91122-8 
9. Yanai H, Yoshida T, Harada T, Matsumoto Y, Nishiaki M, Shigemitsu T, et al. Endoscopic ultrasonography of superficial esophageal cancers using a thin ultrasound probe system equipped with switchable radial and linear scanning modes. Gastrointest Endosc. 1996 Nov; 44(5):578-82.

https://doi.org/10.1016/S0016-5107(96)70012-3

10. Hasegawa N, Niwa Y, Arisawa T, Hase S, Goto H, Hayakawa T. Preoperative staging of superficial esophageal carcinoma: comparison of an ultrasound probe and standard endoscopic ultrasonography. Gastrointest Endosc. 1996 Oct; 44(4):388-93.

https://doi.org/10.1016/S0016-5107(96)70086-X

11. Takemoto T, Yanai H, Tada M, Aibe T, Fujimura H, Murata N, et al. Application of ultrasonic probes prior to endoscopic resection of early gastric cancer. Endoscopy. 1992 May; 24 Suppl 1:329-33.

https://doi.org/10.1055/s-2007-1010493

PMid: 1633775

12. May A, Günter E, Roth F, Gossner L, Stolte M, Vieth $M$, et al. Accuracy of staging in early oesophageal cancer using high resolution endoscopy and high resolution endosonography: a comparative, prospective, and blinded trial. Gut. 2004 May; 53(5):634-40.

https://doi.org/10.1136/gut.2003.029421

PMid:15082579 PMCid:PMC1774048

13. Saitoh Y, Obara T, Einami K, Nomura M, Taruishi M, Ayabe $\mathrm{T}$, et al. Efficacy of high-frequency ultrasound probes for the preoperative staging of invasion depth in flat and depressed colorectal tumors. Gastrointest Endosc. 1996 Jul; 44(1):34-9.

https://doi.org/10.1016/S0016-5107(96)70226-2

14. Yoshida M, Tsukamoto Y, Niwa Y, Goto H, Hase S, Hayakawa T, et al. Endoscopic assessment of invasion of colorectal tumors with a new high-frequency ultrasound probe. Gastrointest Endosc. 1995 Jun; 41(6):587-92.

https://doi.org/10.1016/S0016-5107(95)70196-6

15. Gan SI, Rajan E, Adler DG, Baron TH, Anderson MA, Cash BD, et al. ASGE Standards of Practice Committee, Role of EUS. Gastrointest Endosc. 2007 Sep; 66(3):425-34. https://doi.org/10.1016/j.gie.2007.05.026

PMid: 17643438

16. Dumonceau JM, Deprez PH, Jenssen C, Iglesias-Garcia J, Larghi A, Vanbiervliet G, et al. Indications, results, and clinical impact of endoscopic ultrasound (EUS)-guided sampling in gastroenterology: European Society of Gastrointestinal Endoscopy (ESGE) Clinical Guideline - Updated January 2017. Endoscopy. 2017; 49(7):695-714.

https://doi.org/10.1055/s-0043-109021

PMid:28511234

17. Chang KJ, Erickson RA, Chak A, Lightdale C, Chen YK, Binmoeller KF, et al. EUS compared with endoscopy plus transabdominal US in the initial diagnostic evaluation of patients with upper abdominal pain. Gastrointest Endosc. 2010 Nov; 72(5):967-74.

https://doi.org/10.1016/j.gie.2010.04.007

PMid:20650452 PMCid:PMC3775486
18. Sahai AV, Mishra G, Penman ID, Williams D, Wallace MB, Hadzijahic N, et al. EUS to detect evidence of pancreatic disease in patients with persistent or nonspecific dyspepsia. Gastrointest Endosc. 2000; 52:153-159.

https://doi.org/10.1067/mge.2000.107910

PMid:10922084

19. Agréus L, Svärdsudd K, Nyrén O, Tibblin G. Irritable bowel syndrome and dyspepsia in the general population: overlap and lack of stability over time. Gastroenterology. 1995 Sep; 109(3):671-80.

https://doi.org/10.1016/0016-5085(95)90373-9

20. Lieberman D, Fennerty MB, Morris CD, Holub J, Eisen G, Sonnenberg A. Endoscopic evaluation of patients with dyspepsia: results from the national endoscopic data repository. Gastroenterology. 2004 Oct; 127(4):1067-75.

https://doi.org/10.1053/j.gastro.2004.07.060

PMid:15480985

21. Heikkinen M, Pikkarainen P, Takala J, Julkunen R. General practitioners' approach to dyspepsia. Survey of consultation frequencies, treatment, and investigations. Scand J Gastroenterol. 1996 Jul; 31(7):648-53. https://doi.org/10.3109/00365529609009144

PMid:8819212

22. Krinsky ML. EUS in the initial assessment of upper abdominal pain: time for a paradigm shift? Gastrointest Endosc. 2010 Nov; 72(5):975-7.

https://doi.org/10.1016/j.gie.2010.07.022

PMid:21034898

23. Talley NJ, Vakil N; Practice Parameters Committee of the American College of Gastroenterology. Guidelines for the management of dyspepsia. Am J Gastroenterol. 2005 Oct; 100(10):2324-37.

https://doi.org/10.1111/j.1572-0241.2005.00225.x

PMid:16181387

24. Sahai AV, Penman ID, Mishra G, Williams D, Pearson A, Wallace MB, et al. An assessment of the potential value of endoscopic ultrasound as a cost-minimizing tool in dyspeptic patients with persistent symptoms. Endoscopy. 2001 Aug; 33(8):662-7.

https://doi.org/10.1055/s-2001-16223

PMid:11490381

25. Mirbagheri SA, Mohamadnejad M, Nasiri J, Vahid AA, Ghadimi R, Malekzadeh R. Prospective evaluation of endoscopic ultrasonography in the diagnosis of biliary microlithiasis in patients with normal transabdominal ultrasonography. J Gastrointest Surg. 2005 Sep-Oct;9(7):961-4.

https://doi.org/10.1016/j.gassur.2005.03.002

PMid:16137592

26. Dahan P, Andant C, Lévy P, Amouyal P, Amouyal G, Dumont M, et al. Prospective evaluation of endoscopic ultrasonography and microscopic examination of duodenal bile in the diagnosis of cholecystolithiasis in 45 patients with normal conventional ultrasonography. Gut. $1996 \mathrm{Feb}$; 38(2):277-81.

https://doi.org/10.1136/gut.38.2.277

PMid:8801211 PMCid:PMC1383037 
27. Liu CL, Lo CM, Chan JK, Poon RT, Fan ST. EUS for detection of occult cholelithiasis in patients with idiopathic pancreatitis. Gastrointest Endosc. 2000 Jan; 51(1):28-32. https://doi.org/10.1016/S0016-5107(00)70382-8

28. Sugiyama M, Atomi Y. Endoscopic ultrasonography for diagnosing choledocholithiasis: a prospective comparative study with ultrasonography and computed tomography. Gastrointest Endosc. 1997 Feb;45(2):143-6.

https://doi.org/10.1016/S0016-5107(97)70237-2

29. Shil BC, Saha M, Uddin MR, Saifullah ANM, Mahbub

I, Rashid MMU. Idiopathic Acute Pancreatitis (IAP): The Value of Endoscopic Ultrasound. J Health Med Sci. 2019; 2: 224-229.

https://doi.org/10.31014/aior.1994.02.02.41

30. Ardengh JC, Rosenbaum P, Ganc AJ, Goldenberg A, Lobo EJ, Malheiros CA, et al. Role of EUS in the preoperative localization of insulinomas compared with spiral CT. Gastrointest Endosc. 2000 May; 51(5):552-5. https://doi.org/10.1016/S0016-5107(00)70288-4

31. Anderson MA, Carpenter S, Thompson NW, Nostrant TT, Elta GH, Scheiman JM. Endoscopic ultrasound is highly accurate and directs management in patients with neuroendocrine tumors of the pancreas. Am J Gastroenterol. $2000 \mathrm{Sep}$; 95(9):2271-7.

https://doi.org/10.1111/j.1572-0241.2000.02480.x

PMid: 11007228

32. Khashab MA, Yong E, Lennon AM, Shin EJ, Amateau $\mathrm{S}$, Hruban RH, et al. EUS is still superior to multidetector computerized tomography for detection of pancreatic neuroendocrine tumors. Gastrointest Endosc. 2011 Apr; 73(4):691-6.

https://doi.org/10.1016/j.gie.2010.08.030

PMid:21067742

33. Sugiyama M, Abe N, Izumisato Y, Yamaguchi Y, Yamato $\mathrm{T}$, Tokuhara $\mathrm{M}$, et al. Differential diagnosis of benign versus malignant nonfunctioning islet cell tumors of the pancreas: the roles of EUS and ERCP. Gastrointest Endosc. 2002 Jan; 55(1):115-9.

https://doi.org/10.1067/mge.2002.119604

PMid:11756931

34. Zimmer T, Ziegler K, Bäder M, Fett U, Hamm B, Riecken EO, et al. Localisation of neuroendocrine tumours of the upper gastrointestinal tract. Gut. 1994 Apr; 35(4):471-5.

https://doi.org/10.1136/gut.35.4.471

PMid:8174983 PMCid:PMC1374794

35. Devière J, Finet L, Dunham F, Cremer M. Endoscopic ultrasonography in chronic pancreatitis. Endoscopy. 1994 Nov; 26(9):808-9. https://doi.org/10.1055/s-2007-1009114

PMid:7712997

36. Zuccaro G Jr, Sivak MV Jr. Endoscopic ultrasonography in the diagnosis of chronic pancreatitis. Endoscopy. 1992 May; 24 Suppl 1:347-9.

https://doi.org/10.1055/s-2007-1010497

PMid:1633779

37. Andersen BN, Scheel J, Rune SJ, Worning H. Exocrine pancreatic function in patients with dyspepsia. Hepatogastroenterology. $1982 \mathrm{Feb}$; 29(1):35-7.

38. Schulze S, Thorsgaard Pedersen N, Jorgensen MJ, Mollmann KM, Rune SJ. Association between duodenal bulb ulceration and reduced exocrine pancreatic function. Gut. 1983 Sep; 24(9):781-3.

https://doi.org/10.1136/gut.24.9.781

PMid:6884816 PMCid:PMC1420100

39. Smith RC, Talley NJ, Dent OF, Jones M, Waller SL. Exocrine pancreatic function and chronic unexplained dyspepsia. A case-control study. Int J Pancreatol. 1991 Apr; 8(3):253-62.

40. Chowdhury R, Bhutani MS, Mishra G, Toskes PP, Forsmark CE. Comparative analysis of direct pancreatic function testing versus morphological assessment by endoscopic ultrasonography for the evaluation of chronic unexplained abdominal pain of presumed pancreatic origin. Pancreas. 2005 Jul; 31(1):63-8.

https://doi.org/10.1097/01.mpa.0000164451.69265.80

PMid:15968249

41. Siddiqui AA, Tholey D, Kedika R, Loren DE, Kowalski TE, Eloubeidi MA. Low but significant yield of endosonography in patients with suspected Sphincter of Oddi Dysfunction Type III with normal imaging studies. J Gastrointestin Liver Dis. 2012 Sep; 21(3):271-5.

42. Catalano MF, Sahai A, Levy M, Romagnuolo J, Wiersema M, Brugge W, et al. EUS-based criteria for the diagnosis of chronic pancreatitis: the Rosemont classification. Gastrointest Endosc. 2009 Jun; 69(7):1251-61.

https://doi.org/10.1016/j.gie.2008.07.043

PMid:19243769

43. Trikudanathan G, Munigala S, Barlass U, Malli A, Han Y, Sekulic M, et al. Evaluation of Rosemont criteria for non-calcific chronic pancreatitis (NCCP) based on histopathology - A retrospective study. Pancreatology. 2017 Jan-Feb; 17(1):63-69.

https://doi.org/10.1016/j.pan.2016.10.010

PMid:27836330 